Maiquel Angelo Dezordi Wermuth ${ }^{1}$

Elisa Berton Eidt ${ }^{2}$
Recebido em: 23/02/2016.

Aprovado em: 14/03/2016.

Doutor em Direito Público (UNI-

SINOS). Professor do Mestrado em Direitos Humanos da UNIJUí e do Curso de Graduação em Direito da UNISINOS.

2 Especialista em Direito Público (Universidade Potiguar) e em Direito Previdenciário (Cesusc). Mestranda em Direitos Humanos pela UNIJUí. Procuradora do Estado do Rio Grande do Sul.

\section{A justiça brasileira e o papel das Cortes Internacionais Europeia e interamericana de proteção de direitos humanos em face do direito à razoável duração do processo: a mediação como alternativa à morosidade?*}

\section{Brazilian justice and the role of European and inter-american courts of human rights in face of the right to a trial within a reasonable time: is mediation an alternative to lengthy?}

\section{Resumo}

O presente artigo analisa o direito fundamental à razoável duração do processo e os desafios que esse direito impõe ao Poder Judiciário no Brasil em um contexto de cada vez maior litigiosidade. Na sequência, o artigo apresenta como o tema tem sido tratado pelas Cortes Europeia e Interamericana de Direitos Humanos, de modo a contribuir para o debate acerca da (necessária) construção de um modelo de resolução de conflitos eficiente e apropriado, apresentando, para tanto, o instituto da mediação como condição de possibilidade. Analisa-se, então, a implantação dos institutos da mediação e da conciliação no direito estrangeiro, e a introdução da sua regulação no direito interno, por meio do novo Código de Processo Civil e da Lei da Mediação.

Palavras-chave: Poder judiciário. Duração razoável do processo. Cortes Internacionais de Direitos Humanos. Mediação.

\begin{abstract}
This article analyzes the fundamental right to reasonable processing time and the challenges that this right imposes on the Brazilian Judiciary in a context of increasing litigation. Next, it analyzes how the issue has been dealt with by the European and Inter-American Courts of Human Rights, in order to contribute to the debate about the (necessary) construction of an efficient model of conflict's resolution, presenting, therefore, mediation institute as a condition of possibility. It is analyzed, then, the implementation of the mediation and conciliation institutes in foreign law, and the introduction of its regulation in national law, through the new Civil Procedure Code and the Law Mediation.
\end{abstract}

Keywords: Judiciary. Reasonable time. Human rights international courts. Mediation. 


\section{Considerações Iniciais}

A expressão "processo judicial" remete, instantaneamente, à noção de uma ritualística - em boa medida hermética ${ }^{3}$ - estabelecida pelo legislativo e destinada apenas àqueles que são nela "iniciados", ou seja, aos membros do Poder Judiciário e advogados. Não há dúvidas de que o acesso à justiça se subordina a uma série de procedimentos minuciosamente previstos - tanto em Códigos quanto na legislação esparsa - para que a Jurisdição, enquanto modo de "dizer" o Direito estabelecido abstratamente pelo Estado, se concretize. Em uma perspectiva histórica, é possível perceber que, de um modelo de justiça privativa (ao estilo de Talião), passou-se a uma atividade que passa a ser privativa do Estado e que, em razão disso, passa a ser regida por uma série de procedimentos aos quais os cidadãos que buscam a reparação/ concretização de direitos devem se submeter. A noção de processo enquanto instrumento para a satisfação de direitos materiais ${ }^{4}$, por seu turno, gera uma série de efeitos colaterais que nem sempre são previstos no momento de elaboração das normas processuais.

Vive-se hoje uma era de explosão de direitos e, por consequência, de litigiosidade. No âmbito da América Latina, a transição de regimes autoritários para regimes democráticos foi acompanhada de uma ampla previsão de novos direitos e liberdades, tanto na esfera individual quanto social. $\mathrm{O}$ que antes eram demandas reprimidas transformam-se agora em efetivos direitos a serem usufruídos e exigidos, bem como a possibilitarem uma reparação acaso sejam violados. Nesse marco, Cappelletti ${ }^{5}$ destaca que "a expansão do papel do judiciário representa o necessário contrapeso [...] num sistema democrático de

3 Conforme indaga GARAPON, Antoine. Bem julgar. Lisboa: Instituto Piaget, 1997. p. 18: "Não se destina o ritual igualmente - senão mesmo principalmente - aos profissionais da justiça que são os magistrados e os advogados? Como explicar a sua vivacidade em processos sem público, como sucede no Tribunal Cível ou no Tribunal de Cassação?"

4 Para DINAMARCO, Cândido Rangel. A instrumentalidade do processo. 7. ed. São Paulo: Malheiros, 1999. p. 149, "é vaga e pouco acrescenta ao conhecimento do processo a usual afirmação de que ele é um instrumento, enquanto não acompanhada da indicação dos objetivos a serem alcançados mediante o seu emprego. Todo instrumento, como tal, é meio; e todo meio só é tal e se legitima em função dos fins a que se destina".

5 CAPPELLETTI, Mauro. Juízes legisladores? Trad. Carlos Alberto Alvaro de Oliveira. Porto Alegre: S. A. Fabris, 1993. p. 19. “checks and balances", à paralela expansão dos "ramos políticos" do estado moderno".

$\mathrm{Na}$ acepção de Norberto Bobbio ${ }^{6}$, os direitos do homem passam por constantes processos de modificação e inovação. Essa dinâmica, no entanto, nem sempre é acompanhada pela atuação do Poder Judiciário. Em um ambiente de Estado Democrático de Direito, o sistema de administração da justiça assume responsabilidade tanto pela garantia quanto pela proteção de direitos assegurados pelo ordenamento jurídico. O fato é que esse sistema se depara na contemporaneidade com empecilhos cada vez maiores ao desempenho de sua função, particularmente em razão do excesso de litígios a demandar solução. As razões para dessas dificuldades - que em muitos casos levam ao descrédito do Poder Judiciário - são múltiplas, sendo que, dentre elas, assume especial relevância o excesso de artifícios previstos no rito processual.

Com efeito, o exercício do direito de ação pelo jurisdicionado faz movimentar todo o aparato de sujeitos e de órgãos estatais responsáveis pela "administração da justiça”. Advogados, defensores, promotores, juízes e demais servidores dos órgãos julgadores tanto de primeira, quanto de segunda e até mesmo de quarta instância são envolvidos no processo. Ocorre que a "orquestra" dos instrumentos colocados à disposição desses atores há muito tempo deixou de acompanhar aquele ritmo considerado desejável para o alcance de uma solução adequada aos litígios que são levados a juízo. A morosidade que subjaz aos instrumentos não é capaz de fazer frente ao ritmo cada vez mais acelerado das demandas, fazendo com que o jargão popular segundo o qual "a justiça que tarda é falha" seja em cada processo repristinado.

Em boa medida, isso se deve ao fato de que muitos desses instrumentos - cujo paradigma é o processo de conhecimento pelo rito ordinário, considerado enquanto modelo universal de solução de controvérsias - foram gestados com base em um ideal de racionalidade científica pugnado pela Modernidade, que acabou gerando para o processo uma espécie de "carência" no que se refere à percepção social ${ }^{7}$. O processo, assim como os seus

BOBBIO, Norberto. A era dos direitos. Rio de Janeiro: Campus, 1992. p. 18-19.

7 Como adverte SALDANHA, Jânia Maria Lopes. Da teoria geral do processo à teoria da tradução: um aporte da sociologia das ausências e das emergências. In: DIDIER JUNIOR, Fredie; JORDÃO, Eduardo Ferreira (Org.). Teoria do processo: panorama doutrinário mundial. Salvador: JusPodivm, 2007. p. 389-428, esse quadro foi responsável 
operadores, acabou, nesse sentido, isolados de toda uma gama de experiências de resolução de conflitos mais ricas e eficientes do ponto de vista da efetividade do que as apresentadas pelo rito moroso e praticamente obsoleto do processo de conhecimento.

O tema da lentidão da justiça não é exclusividade brasileiro, conforme se demonstrará no presente texto. A morosidade nos processos judiciais se configura em um problema que atinge boa parte dos países, tanto europeus quanto americanos. A variação reside apenas nas formas adotadas por cada país no enfrentamento do problema.

Nesse sentido, convém salientar que tanto a Corte Interamericana quanto a Corte Europeia de Direitos Humanos, seja por meio de Convenções ou da sua jurisprudência, são responsáveis pelo estabelecimento de alguns critérios que são utilizados para definir em termos objetivos em que consiste um processo com uma tramitação razoável, o que pode orientar a deteç̧ão e condução do problema nos países que integram o Sistema europeu e interamericano de Direitos Humanos, até mesmo para evitar que esses países sejam demandados perante as Cortes Internacionais referidas.

Diante do quadro esboçado, o presente artigo objetiva ao desenvolvimento de uma reflexão acerca do tema da duração razoável do processo e os desafios que esse direito fundamental impõe ao Poder Judiciário no Brasil (parte 1). Na sequência, analisa-se como o tema tem sido tratado pelas Cortes Europeia (parte 2) e Interamericana (parte 3) de Direitos Humanos, de modo a contribuir para o debate acerca da (necessária) construção de um modelo de resolução de conflitos eficiente e apropriado para responder às demandas da cidadania na sociedade plural que o atual contexto histórico-político brasileiro requer, apresentando, para tanto, o instituto da mediação como condição de possibilidade.

\section{0 direito fundamental à razoável duração do processo no brasil e os desafios impostos ao poder judiciário para sua implementação}

Falar em "crise" no contexto da atuação do Poder Judiciário brasileiro não configura nenhuma novidade. $\mathrm{O}$

pela criação de uma espécie de "monocultura” do processo de conhecimento, responsável, paradoxalmente, pela sua crise contemporânea, que decorre tanto da sua morosidade quanto da obsolescência de suas estruturas diante das demandas cada vez mais complexas da cidadania. monopólio estatal da jurisdição e a burocracia que subjaz (historicamente) aos serviços públicos no Brasil se deparam todos os dias com litígios cada vez mais complexos que emergem de uma sociedade acelerada e tecnológica inserida no contexto da globalização. No caso do Brasil, para além da globalização houve, em um curto espaço de tempo, a transformação da estrutura de sua população de rural para urbana -, de modo a contribuir para o aumento dos conflitos nas cidades ${ }^{8}$.

Da mesma forma, a Constituição de 1988 consagra em seu texto não apenas os direitos individuais, mas uma extensa lista de direitos sociais e coletivos, além de programas de implantação de políticas públicas. Com isso, o Poder Judiciário tem sua margem de atuação alargada e passa a assumir relevante papel na garantia desses novos direitos. Não obstante o protagonismo alcançado ao Judiciário pela carta constitucional - e talvez por causa dele -, a justiça brasileira não mais satisfaz a população que demanda seus serviços ${ }^{9}$. Em boa medida, isso decorre do fato de que o Judiciário brasileiro foi "preparado para lidar com conflitos interindividuais, próprios de um modelo liberal-individualista", não se mostrando "preparado para o enfrentamento dos problemas decorrentes da transindividualidade, própria do (novo) modelo advindo do Estado Democrático de Direito previsto na Constituição promulgada em 1988" 10 .

No entanto, conforme adverte SADEK, Maria Tereza. Judiciário: mudanças e reformas. Estudos avançados, São Paulo, v. 18, n. 51, p. 79-101, jan./abr. 2004, a transformação de sociedade agrária e rural para industrial e urbana seria suficiente para o aumento dos litígios, o que não ocorreu em larga escala devidos à "ausência de vida democrática e pelo descrédito na justiça”. São inúmeros os cidadãos que permanecem desconhecendo os seus direitos ou que veem a justiça como custosa e lenta.

9 "Essa descrença na Justiça se dá não só pela distância entre o cidadão comum, os ritos e a linguagem que envolvem os processos judiciais, mas também pelo tempo percorrido por cada procedimento (tradicionalmente longo), pela inadequação das decisões vertidas ante a complexidade dos litígios e pela impossibilidade do seu cumprimento. O que verifica, então, é a desconexão entre o aparelho judicial e o sistema político e social, distanciando-se a lei (e, por conseguinte, sua interpretação e sua aplicação) da sociedade na qual se encontra inserida, não correspondendo, assim, à expectativa de tratamento adequado de conflitos." SPENGLER, Fabiana. Da jurisdição à mediação: por uma outra cultura no tratamento de conflitos. Ijuí: Unijuí, 2010. p. 111.

10 STRECK, Lenio Luiz. Hermenêutica jurídica e $(m)$ crise: uma exploração hermenêutica da construção do Direito. 8. ed. rev. e atual. Porto Alegre: Livraria do Advogado, 2008. p. 51. 
De acordo com Morais ${ }^{11}$, vive-se um "momento de desacomodação interna”, marcado por um “aumento extenso e intenso de reivindicações de acesso à Justiça, quantitativa e qualitativamente falando". Esse movimento contrapõe-se a "instrumentos jurisdicionais notoriamente insuficientes e ineficientes para atender e satisfazer subjetiva e objetivamente o conjunto de demandas que lhe são propostas".

Essa ineficiência do sistema judiciário é constatada e comprovada com base em números levantados em recentes estatísticas. O Conselho Nacional de Justiça, no relatório intitulado "Justiça em Números", elaborado anualmente, trouxe à tona, no documento relativo ao ano de 2014, dados que apontam para um crescimento vertiginoso de quase 12 milhões $(13,9 \%)$ de processos em tramitação desde o ano de 2009. Some-se a isso o fato de que, segundo o relatório, desde o ano de 2011, o número de processos baixados mostra-se inferior ao dos novos casos. O estudo também demonstra que, mesmo diante do aumento dos investimentos no aparelhamento do Poder Judiciário, bem como do incremento no número de juízes e de servidores, o número de processos em tramitação aumentou, ao contrário do que se verifica em relação ao percentual dos processos baixados ${ }^{12}$.

Diante desses dados, pode-se inferir que a prestação do serviço jurisdicional, no Brasil não tem acompanhado a demanda social pela resolução de um número cada vez maior de litígios que emergem na contemporaneidade. Particularmente quando se constata que há investimentos e acréscimo de pessoal no âmbito do Poder Judiciário. Pode-se afirmar, nesse sentido, que a estrutura do Judiciário, assim como a mera sofisticação do proces-

11 MORAIS, Jose Luis Bolzan de. Mediação e arbitragem: alternativas à jurisdição. Porto Alegre: Livraria do Advogado, 1999. p. 106.

12 Resume o relatório: "Em linhas gerais, há um crescimento da litigiosidade de forma mais acentuada que os recursos humanos e as despesas. Enquanto que, no último ano (2013), houve crescimento de $1,5 \%$ nos gastos totais, $1,8 \%$ no número de magistrados e $2 \%$ no de servidores, tramitaram cerca de $3,3 \%$ a mais de processos nesse período, sendo $1,2 \%$ a mais de casos novos e $4,2 \%$ de casos pendentes de anos anteriores. Já o total de processos baixados aumentou em apenas $0,1 \%$ em relação ao ano anterior, ou seja, o aumento na estrutura orçamentária, de pessoal e da demanda processual dos tribunais não resultou necessariamente em aumento, proporcional, da produtividade" Disponível em: <http://www.cnj.jus.br/programas-de-a-a-z/ eficiencia-modernizacao-e-transparencia/pj-justica-em-numeros/relatorios>. Acesso em: 09 dez. 2015. so $^{13}$ não respondem a contento àquelas expectativas da cidadania no que se refere à resolução de conflitos de modo célere e eficaz.

A fim de corroborar tal assertiva, pesquisa realizada pela Fundação Getúlio Vargas, conforme relatório Índice de Confiança no Judiciário (ICJBrasil), referente ao segundo e ao terceiro trimestre de $2014^{14}$ revela que "a má avaliação do Judiciário como prestador de serviços públicos segue a tendência, já identificada nos períodos anteriores. Para 89\% dos entrevistados o Judiciário é moroso, resolvendo os conflitos de forma muito lenta ou muito lentamente". A pesquisa também aponta que o percentual dos entrevistados que confiam no Judiciário alcançou o patamar de 29\%. Ainda, dentre as 11 (onze) instituições avaliadas, o Judiciário assume a nona posição, considerado mais confiável apenas que o Congresso Nacional e os partidos políticos (que sempre ocupam a última posição).

Em relação à morosidade, observa-se que a "era dos direitos" deflagrada pela Constituição Federal de 1988 foi acompanhada pela garantia de um acesso amplo e irrestrito à justiça (art. 5º, inciso XXXV) e do devido processo legal (art. $5^{\circ}$, inciso LIV). No entanto, o legislador constitucional não fez qualquer menção, no Texto Constitucional originário, ao direito à razoável duração do processo para o alcance da tutela jurisdicional de direitos, como salienta José Rogério Cruz e Tucci ${ }^{15}$.

$\mathrm{Na}$ ótica do sobredito autor ${ }^{16}$, não se pode deixar de considerar que, antes mesmo da modificação operada

13 Nos dizeres de NALINI, José Renato. Morosidade do Judiciário: causas normativas, conjunturais e culturais. Propostas de enfrentamento. Revista Forense, Rio de Janeiro, v. 104, n. 399, p. 129-144, set.-out. 2008. p. 132: "O processo brasileiro ainda é sofisticado demais, considerada a heterogeneidade da sociedade nacional e, principalmente, a situação de penúria da grande maioria da população. Verdade que convivem no Brasil realidades múltiplas e díspares. $\mathrm{O}$ processo vem se pautando por um nível superior, como se a imensa maioria dos destinatários não fosse a legião dos despossuídos. O processo é complexo, pleno de artimanhas e propiciador de alongamento na duração de qualquer feito, por singelo que possa parecer o objeto".

14 FUNDAÇÃO GETÚLIO VARGAS. Indice de Confiança na Justiça brasileira: ICJBrasil. Disponível em: <http://bibliotecadigital.fgv.br/dspace/handle/10438/6618>. Acesso em: 16 nov. 2015.

15 TUCCI, José Rogério Cruz e. Garantias constitucionais da duração razoável e da economia processual no projeto do código de processo civil. Revista de Processo, São Paulo, v. 192, p. 193-208, fev. 2010.

16 TUCCI, José Rogério Cruz e. Garantias constitucionais da duração razoável e da economia processual no projeto do código de processo civil. Revista de Processo, São Paulo, v. 192, p. 193-208, fev. 2010. 
no rol de direitos fundamentais do art. $5^{\circ}$ da Constituição pela Emenda Constitucional no 45/2004, o Brasil, por ser país signatário do Pacto de São José da Costa Rica, já se encontrava adstrito à regra de uma razoável duração do processo. Com efeito, o referido diploma, ratificado pelo Brasil por meio do Decreto ${ }^{\circ}$ 678, de 1992, dispõe, em seu art. 8 , inciso I, que:

toda pessoa terá o direito de ser ouvida, com as devidas garantias e dentro de um prazo razoável, por um juiz ou Tribunal competente, independente e imparcial, estabelecido anteriormente por lei, na apuração de qualquer acusação penal formulada contra ela, ou na determinação de seus direitos e obrigações de caráter civil, trabalhista, fiscal ou de qualquer outra natureza.

Ocorre que, mesmo diante da incorporação do documento ao ordenamento jurídico nacional, a Emenda Constitucional no 45/2004 introduziu ao catálogo de direitos fundamentais do art. $5^{\circ}$ da Constituição o inciso LXXVIII, dispondo que "a todos, no âmbito judicial e administrativo, são assegurados a razoável duração do processo e os meios que garantam a celeridade de sua tramitação".

O dispositivo em comento pode ser compreendido como corolário do princípio da eficiência, basilar para as atividades da Administração Pública, conforme dispõe o caput do artigo 37 da Constituição. Ora, se serviço da Justiça configura-se enquanto uma das atividades da Administração Pública, afigura-se lógico que ele também se submeta àqueles princípios que a regem. Como destaca Silva $^{17}$, na medida em que o Estado-juiz, historicamente, avocou para si a função de dizer o direito, solucionando os litígios que lhe são apresentados pela sociedade, ele deve exercer essa tarefa com eficiência, bem como atender aos reclamos dessa mesma sociedade. Em não o fazendo, o Judiciário estaria a frustrar as expectativas dos cidadãos, o que poderia gerar insegurança jurídica, bem como causar instabilidade social e prejudicar a concretização dos direitos fundamentais.

Evidencia-se, portanto, que, em meio a um panorama que já apontava para a crise da Jurisdição, o Constituinte incorporou uma nova e fundamental garantia àqueles que se socorrem do Poder Judiciário brasileiro. Buscou-se, com isso, substancialmente, resgatar a credi-

17 SILVA, Enio Moraes da. A garantia constitucional da razoável duração do processo e a defesa do Estado. Revista de Informação Legislativa, Brasília, v. 43, n. 172, p. 23-36, out./ dez. 2006. bilidade dessa função estatal, bem como impor obrigações à administração da Justiça, imprescindíveis ao atendimento do novo comando constitucional, afinal, mesmo diante das mazelas que o acometem, o Judiciário não poderia ser relegado a segundo plano - ou até mesmo descartado - no que se refere à resolução de litígios.

Sobre o tema, salienta Spengler ${ }^{18}$ que a crise do Judiciário é também uma crise do Estado e do Direito. Nesse sentido, faz-se necessária a criação de novas estratégias de atuação da função jurisdicional, de modo a fazer com que o cidadão volte a acreditar na Justiça. Segundo a autora, existem algumas razões importantes para isso: "a primeira é a de que uma sociedade complexa não pode dispensar um sistema de regras e, consequentemente, uma jurisdição que garanta o seu respeito ou sanção (nos casos de infração)"; por outro lado, "renunciar à Justiça não é possível sob pena de novamente ser instalada a guerra de todos contra todos no mais típico estado de natureza."

Nesse sentido, a Emenda Constitucional $n^{\circ} 45$, ao promover a chamada "Reforma do Judiciário", foi responsável pela introdução de inovações importantes ao Texto Constitucional, tanto no que se refere a uma aplicação mais uniforme do direito - no caso das súmulas vinculantes - quanto no que concerne à fiscalização e ao aperfeiçoamento da gestão dos órgãos judiciários - com a criação do Conselho Nacional de Justiça (CNJ).

Passados dez anos da promulgação da Emenda, interessante trazer à tona recente pesquisa realizada pela Associação dos Magistrados do Brasil - AMB, intitulada "O uso da Justiça e o litígio no Brasil" ${ }^{19}$. Com base em dados coletados em onze unidades da Federação, foram extraídos os cem maiores litigantes que se encontram no polo ativo e no polo passivo dos processos judiciais, tanto em Primeiro e Segundo Grau como nas Turmas Recursais. A conclusão do relatório é de que "um número extremamente reduzido de atores é responsável por, pelo menos, metade destes processos". Administração Pública e Setor Financeiro lideram o ranking.

Daí ser possível afirmar, nos termos da conclusão

18 SPENGLER, Fabiana. Da jurisdição à mediação: por uma outra cultura no tratamento de conflitos. Ijuí: Unijuí, 2010. p. 116-117.

19 ASSOCIAÇÃO DOS MAGISTRADOS DO BRASIL. O uso da Justiça e o litígio no Brasil. Disponível em: <https://www. placardajustica.com.br/assets/files/placardajustica_o_uso_ da_justica_e_o_litigio_no_brasil.pdf $>$. Acesso em: 01 set. 2015. 
da pesquisa, "que a política de estímulo ao planejamento estratégico e de estabelecimento de metas para os tribunais não vem surtindo os efeitos desejados para melhorar a eficiência e descongestionar o Judiciário". A concentração dos processos em um número reduzido de litigantes contribui para manter a Justiça inacessível e morosa, sobretudo porque, em muitos casos, se trata de atores que se beneficiam da lentidão da prestação jurisdicional a fim de postergar o cumprimento de suas obrigações e de camuflar suas deficiências. Dessa forma, a atenção deve se voltar para as causas da elevada litigiosidade e maneiras de preveni-la. A prevenção de litígios e a solução alternativa de conflitos, portanto, ganha ainda mais destaque como medida eficaz para um Judiciário célere e eficiente.

Nesse ponto, é importante observar que, ao se falar em eficiência na prestação jurisdicional, bem como na razoável duração do processo, as alternativas buscadas para atingir a essas finalidades não se limitam, necessariamente, às estruturas do Poder Judiciário. Tampouco se limitam à exclusividade do processo judicial como meio para a resolução de conflitos. Segundo Saldanha ${ }^{20}$, essas alternativas perpassam por uma inteligibilidade recíproca entre diversas experiências disponíveis, tanto em âmbito interno quanto em âmbito externo:

a inteligibilidade recíproca entre experiências disponíveis pode decorrer, no âmbito interno ou do direito nacional, das experiências jurisdicionais inovadoras tendentes a simplificar o processo, dar mais poderes aos juízes, como também o contrário, provocar a divisão desse poder com outros atores, não menos importantes. Ainda no âmbito interno, as experiências disponíveis podem ser encontradas nos espaços de solução de conflitos presentes no interior da sociedade civil.

Por outro lado, no âmbito externo ou do direito comparado, sobretudo as experiências do common law podem servir de inspiração para a criação de outros institutos jurídico-processuais mais consentâneos com a massificação dos direitos e com a sua constitucionalização.

Trata-se de uma perspectiva que vai ao encontro da análise de Watanabe ${ }^{21}$, para a qual, em boa medida, a

20 SALDANHA, Jânia Maria Lopes. Da teoria geral do processo à teoria da tradução: um aporte da sociologia das ausências e das emergências. In: DIDIER JUNIOR, Fredie; JORDÃO, Eduardo Ferreira (Org.). Teoria do processo: panorama doutrinário mundial. Salvador: JusPodivm, 2007. p. 413.

21 WATANABE, Kazuo. Política Pública do Poder Judiciário nacional para tratamento adequado dos conflitos de interesses. Revista de Processo, São Paulo, v. 195, p. 381-389, maio 2011. crise do Judiciário decorre do mecanismo por ele predominantemente utilizado, qual seja, o da solução adjudicada dos conflitos, por meio de uma sentença judicial. Para o autor, a predominância desse modelo gera uma espécie de "cultura da sentença", cuja consequência é o aumento de recursos que, por sua vez, explicam o congestionamento tanto das instâncias iniciais quanto dos Tribunais Superiores e até mesmo do Supremo Tribunal Federal.

Com efeito, consoante os dados levantados pelo Conselho Nacional de Justiça no já referido relatório "Justiça em Números", a celeridade da tramitação do processo judicial não depende somente de investimentos no Poder Judiciário. Ela está diretamente relacionada, também, ao fomento à implementação de outros meios de resolução de litígios.

É preciso ter em mente, nesse sentido, que, como assevera Humberto Dalla Bernardina de Pinho ${ }^{22}$, apenas a jurisdição é monopólio do Estado, mas não a solução dos conflitos. Nessa esteira, o Conselho Nacional de Justiça, ao editar a Resolução no 125 (29 de novembro de 2010), institucionalizou a denominada "Política Judiciária Nacional de tratamento adequado dos conflitos de interesses no âmbito do Poder Judiciário". Segundo a Resolução, passa a ser incumbência dos órgãos judiciários a oferta de mecanismos alternativos para a solução de controvérsias, "em especial os chamados consensuais, como a mediação e a conciliação" 23 .

Essa inserção da cultura de métodos alternativos de solução de conflitos deflagrada pela Resolução em comento repercutiu também na redação do novo Código de Processo Civil. Como se infere da leitura da Lei 13.105/2015, há uma seção específica (Seção V, Capítulo III) para tratar dos conciliadores e dos mediadores judiciais (arts. 165 a 175) ${ }^{24}$. Não obstante isso, na

22 PINHO, Humberto Dalla Bernardina de. O novo CPC e a mediação: reflexões e ponderações. Revista de Informação Legislativa, Brasília, v. 48, n. 190, t. 1, p. 219-235, abr./jun. 2011.

23 "Art. $1^{\circ}$ Fica instituída a Política Judiciária Nacional de tratamento dos conflitos de interesses, tendente a assegurar a todos o direito à solução dos conflitos por meios adequados à sua natureza e peculiaridade. (Redação dada pela Emenda $\mathrm{n}^{\circ}$ 1, de 31.01.13) Parágrafo único. Aos órgãos judiciários incumbe oferecer mecanismos de soluções de controvérsias, em especial os chamados meios consensuais, como a mediação e a conciliação bem assim prestar atendimento e orientação ao cidadão. Nas hipóteses em que esse atendimento de cidadania não for imediatamente implantado, esses serviços devem ser gradativamente ofertados no prazo de 12 (doze) meses".

24 "O Projeto se preocupa, especificamente, com a atividade 
condução do processo, segundo o Novo Código, o juiz deverá "promover, a qualquer tempo, a autocomposição, preferencialmente com auxílio de conciliadores e mediadores judiciais" (art. 139, inciso V). Trata-se, evidentemente, de uma manifestação, na nova legislação processual civil brasileira, "de uma tendência mundial de abrir o procedimento comum para os meios alternativos de solução de disputas, tornando a solução judicial uma espécie de última ratio para a composição dos litígios" ${ }^{25}$.

Quando se está a tratar de meios alternativos de solução de conflitos, é de curial relevância pontuar que a sua prática não tem por objetivo única e exclusivamente "desafogar" ${ }^{26}$ o Poder Judiciário. Pelo contrário, o objetivo é o de trazer a possibilidade de um tratamento mais adequado ao conflito, por meio de uma solução consentida e construída pelas partes nele envolvidas, a partir de estratégias que fogem ao código binário ganhar/perder e que, em razão disso, "permitem aumentar a compreensão e o reconhecimento dos participantes", bem como "construir possibilidades de ações coordenadas - mesmo que na diferença -“, e, ainda, "incrementar diálogos e a capacidade de pessoas e comunidades que possam/queiram comprometer-se responsavelmente para com decisões e acordos participativos, especificando as mudanças que ocorrerão."27

de mediação feita dentro da estrutura do Poder Judiciário. Isso não exclui, contudo, a mediação prévia ou mesmo a possibilidade de utilização de outros meios de solução de conflitos (art. 153)" PINHO, Humberto Dalla Bernardina de. O novo CPC e a mediação: reflexões e ponderações. $R e$ vista de Informação Legislativa, Brasília, v. 48, n. 190, t. 1, p. 219-235, abr./jun. 2011. p. 227.

25 PINHO, Humberto Dalla Bernardina de. O novo CPC e a mediação: reflexões e ponderações. Revista de Informação Legislativa, Brasília, v. 48, n. 190, t. 1, p. 219-235, abr./jun. 2011. p. 173.

26 "Os métodos alternativos/consensuais/ adequados de resolução de conflitos não foram criados ou aprimorados para substituir o modelo tradicional de utilização do sistema judicial, nem para descongestioná-lo (não havendo, inclusive, qualquer relação de hierarquia entre o Poder Judiciário e os mecanismos consensuais), mas sim para propiciar opções viáveis, alternativas para as pessoas que buscam soluções diferenciadas, específicas, e, talvez, especializadas para suas distintas inter-relações”. SALES, Lilia Maria de Morais Sales; RABELO, Cilana de Morais Soares. Meios consensuais de solução de conflitos: instrumentos de democracia. Revista de Informação Legislativa, Brasília, v. 46, n. 182, p. 75-88, abr./jun. 2009. p. 77.

27 SPENGLER, Fabiana. Da jurisdição à mediação: por uma outra cultura no tratamento de conflitos. Ijuí: Unijuí, 2010. p. 296.
Com efeito, de acordo com Morais ${ }^{28}$, a partir dos mecanismos consensuais de solução de litígios

em vez da delegação do poder de resposta, há uma apropriação pelos envolvidos do poder de geri-los, caracterizando-se pela proximidade, oralidade, ausência/diminuição de custos, rapidez e negociação, [...] onde na discussão do conflito são trazidos à luz todos os aspectos que envolvem o mesmo, não se restringindo apenas àqueles dados deduzidos na petição inicial e na resposta de uma ação judicial cujo conteúdo vem pré-definido pelo direito positivo e é resguardado pela atuação saneadora do magistrado na condução do processo.

A efetiva participação das pessoas envolvidas na resolução do litígio, rompendo com o código binário ganho perda, afigura-se como a maior contribuição para que os métodos alternativos de resolução de controvérsias sejam realmente efetivos. Na busca por alternativas à morosidade, o deslocamento do protagonismo do Poder Judiciário para as partes, agora expressamente albergado pelo novo Código de Processo Civil, afigura-se como condição de possibilidade para a superação das deficiências referidas no relatório "Justiça em números"29.

Não se trata, no entanto, de considerar que a reforma legislativa em questão fará as vezes de panaceia universal. Entende-se que muito ainda precisa ser feito para que níveis satisfatórios sejam alcançados. E isso depende, também, como salientam Pedroso e $\mathrm{Cruz}^{30}$, pela “adopção de um modelo distinto do actual, compreendendo uma articulação entre os vários tipos de reformas propostas e designadamente a 'criação' de processos, instâncias, e instituições relativamente descentralizadas, informais e desprofissionalizadas". Essas instituições devem atuar de modo substitutivo ou complementar, em áreas determinadas, à administração tradicional da justiça, tornando-a “em geral mais rápida, mais barata e mais acessível".

28 MORAIS, Jose Luis Bolzan de. Mediação e arbitragem: alternativas à jurisdição. Porto Alegre: Livraria do Advogado, 1999. p. 128.

29 Com efeito, consta no Relatório que "a taxa de congestionamento passou de 70\% para 70,9\%, ou seja, de 100 processos que tramitaram no ano de 2013, aproximadamente 29 foram baixados no período. A alta taxa de congestionamento é causada pela grande quantidade de processos pendentes na fase de execução da primeira instância, tendo em vista que a taxa de congestionamento é de aproximadamente $86 \%$ nessa fase, enquanto, na fase de conhecimento, o percentual cai para $60 \% "$

30 PEDROSO, João; CRUZ, Cristina. A arbitragem institucional: um novo modelo de administração de justiça: o caso dos conflitos de consumo. Coimbra, 2000. Disponível em: $<$ http://opj.ces.uc.pt/portugues/relatorios/relatorio_0,9. html>. Acesso em: 08 set. 2015. 
Evidencia-se, portanto, que o modelo da solução adjudicada de conflitos não se presta a equacionar o litígio que demanda resolução. Ocorre, nesse sistema, apenas a transferência do conflito para uma tumultuosa fase de cumprimento do que resta definido pelo juiz na sentença ${ }^{31}$.

A via do processo judicial polariza as partes entre aquele que ganha e aquele perde, no entanto, com poucas garantias de que aquele que obteve o reconhecimento de seu direito terá eficácia na reparação de sua lesão. Os dados levantados pelo relatório “Justiça em Números" revelam que a satisfação do direito exige imenso esforço - e paciência - da parte interessada, não obstante já possuir o provimento judicial a seu favor ${ }^{32}$. Os métodos consensuais de conflitos, por outro lado, facilitam a aceitação - e o consequente cumprimento - daquilo que restou decidido, justamente porque não houve imposição, mas sim uma construção conjunta quanto a melhor maneira de apaziguar o conflito. É o que conclui Cappelletti, com sua terza ondata de soluções práticas para tornar a justiça mais acessível:

Ademais, parece que tais decisões são mais facilmente aceitas do que decretos judiciais unilaterais, uma vez que eles se fundam em acordo já

31 "Numa análise lógica, findo o processo, é consequência esperada o aperfeiçoamento daquilo que restou especificado na decisão diante da produção dos seus efeitos por meio da execução, etapa essa que, após ser concluída, proporcionará a eficácia real da decisão. Nesse sentido, a prestação jurisdicional só se completa quando a decisão prolatada ganha eficácia, ou seja, produz os efeitos esperados e orientados diante da fundamentação da existência de um direito. Do contrário, além de fraudar o direito afirmado, fraudar-se-ia, como um todo, o próprio direito à intermediação jurisdicional estatal; direito esse constitucionalmente garantido". ZAMPIERI, Natália. A efetividade da razoável duração do processo e a gestão pública. Revista de Processo, São Paulo, v. 234, p. 13-30, ago. 2014. p. 21.

$32 \mathrm{Na}$ análise de Dinamarco sobre a finalidade do processo judicial, também este deve se destinar a uma maior pacificação social, não se tratando de um mero instrumento, mas sim, de um meio de se alcançar diversos objetivos: "Embora incompleto ainda o quadro dos escopos da jurisdição e carente de melhores definições, é inegável a tendência a abandonar a unidade teleológica tradicional [...] Mas as explicações meramente jurídicas da destinação do processo pecam justamente por deixarem na sombra o valor humano perseguido por meio do exercício da jurisdição. Saia-se do plano do direito e passe-se ao da sociedade ao qual ele se destina, e então sentir-se-á que seria inteiramente inaceitável e mesmo logicamente sem explicação a busca da paz entre pessoas em um caso concreto, sem saber se elas estão em real conflito". DINAMARCO, Cândido Rangel. A instrumentalidade do processo. 7. ed. São Paulo: Malheiros, 1999. p. 95. estabelecido entre as partes. É significativo que um processo dirigido para a conciliação - ao contrário do processo judicial, que geralmente declara uma parte "vencedora" e a outra "vencida" - ofereça a possibilidade de que as causas mais profundas de um litígio sejam examinadas e restaurado um relacionamento complexo e prolongado. $^{33}$

A solução consensual, participativa, com senso de autorresponsabilidade das partes envolvidas permite o cumprimento espontâneo da decisão dada ao litígio, eliminando a morosa fase de execução de sentença e colocando uma verdadeira luz sobre o que se pode definir como razoável duração do processo. Esses mecanismos, para além da redução da quantidade de atos processuais, a fim de dar cabo a uma decisão imposta, servem para estimular a democracia, favorecendo o empoderamento da cidadania que se transforma em protagonista da construção de soluções, em detrimento do mero "cidadão-cliente" do Poder Judiciário ${ }^{34}$.

Uma vez delineadas as medidas que estão sendo adotadas pelo sistema judiciário brasileiro com o escopo de aperfeiçoamento da administração da justiça, na sequência busca-se investigar a atenção que tem sido dispensada pelos demais países ao tema. A abordagem perpassará pelo papel desempenhado, nesse sentido, pelas instâncias supranacionais, especificamente a Corte Europeia (parte 2) e a Corte Interamericana de Direitos Humanos (parte 3).

\section{0 direito à razoável duração do processo na realidade europeia e o papel desempenha- do pela Corte Europeia De Direitos Humanos}

Com o final da II Guerra Mundial, foi dado início a um movimento de integração dos países europeus, a partir do estabelecimento da Convenção Regional Europeia de Direitos Humanos. Segundo Mazzuoli ${ }^{35}$, a Convenção em questão consiste em um "tratado-regente do sistema regional europeu de proteção dos direitos humanos, tal como a Convenção Americana sobre Direitos Humanos é

33 CAPPELLETTI, Mauro. Acesso à justiça. Porto Alegre: S. A. Fabris, 1988. p. 83-84

34 SALES, Lilia Maria de Morais Sales; RABELO, Cilana de Morais Soares. Meios consensuais de solução de conflitos: instrumentos de democracia. Revista de Informação Legislativa, Brasília, v. 46, n. 182, p. 75-88, abr./jun. 2009.

35 MAZZUOLI, Valério de Oliveira. O Sistema Regional Europeu de Proteção dos Direitos Humanos. Revista de Direito Constitucional e Internacional, São Paulo, v. 71, p. 345374, abr./jun. 2010. 
o principal instrumento sobre direitos humanos do sistema interamericano".

No texto da Convenção Europeia, observa-se o intuito no sentido da criação de padrões mínimos de proteção aos direitos e liberdades fundamentais. Com isso, os Estados-partes se comprometam a não contrariar as normas da Convenção. Caso o façam, sujeitam-se a demandas perante a Corte Europeia de Direitos Humanos ${ }^{36}$. A Convenção prevê, em seu art. $6^{\circ}$, inciso I, dentre outros direitos fundamentais, que

\begin{abstract}
qualquer pessoa tem direito a que a sua causa seja examinada, equitativa e publicamente, num prazo razoável por um tribunal independente e imparcial, estabelecido pela lei, o qual decidirá, quer sobre a determinação dos seus direitos e obrigações de carácter civil, quer sobre o fundamento de qualquer acusação em matéria penal dirigida contra ela ${ }^{37}$
\end{abstract}

Debruçando-se sobre o tema em questão, Cruz e Tucci $^{38}$ salientam que foi a partir da edição desse diploma legal supranacional que o direito ao processo "sem dilações indevidas passou a ser concebido como um direito subjetivo constitucional, de caráter autônomo, de todos os membros da coletividade (incluídas as pessoas jurídicas) à tutela jurisdicional dentro de um prazo razoável", o que decorre "da proibição do non liquet, vale dizer, do dever que têm os agentes do Poder Judiciário de julgar as causas com estrita observância das normas de direito positivo".

Com base na análise dos diplomas legais vigentes na maioria dos países que compõem a Europa, é possível concluir que há uma preocupação europeia com a otimização da administração da justiça por meio da qualidade do serviço judiciário, particularmente em razão da duração razoável do processo $^{39}$. Cruz e Tucci $^{40}$ salientam,

36 MAZZUOLI, Valério de Oliveira. O Sistema Regional Europeu de Proteção dos Direitos Humanos. Revista de Direito Constitucional e Internacional, São Paulo, v. 71, p. 345374, abr./jun. 2010.

37 Texto da Convenção Europeia dos Direitos do Homem. Disponível em: <www.echr.coe.int/Documents/Convention_POR.pdf $>$. Acesso em: 12 nov. 2015.

38 TUCCI, José Rogério Cruz e. Garantias constitucionais da duração razoável e da economia processual no projeto do código de processo civil. Revista de Processo, São Paulo, v. 192, p. 193-208, fev. 2010.

39 Constituição Italiana, art. 111; Constituição Espanhola, art. 24.2, Constituição Portuguesa, art. 20.4.

40 TUCCI, José Rogério Cruz e. Garantias constitucionais da duração razoável e da economia processual no projeto do código de processo civil. Revista de Processo, São Paulo, v. 192, p. 193-208, fev. 2010. a propósito, que é impossível fixar a priori uma regra específica, determinante da violação à garantia da tutela jurisdicional de um prazo razoável. A partir disso, explica o processualista que no julgamento do caso Capuano (1987), a Corte Europeia de Direitos do Homem elaborou alguns critérios que devem ser levados em consideração na apuração da efetiva extrapolação de um tempo razoável para a tramitação processual. Os critérios em questão podem ser sintetizados em três: I) complexidade do assunto; II) comportamento dos litigantes e de seus procuradores e III) a atuação do órgão jurisdicional ${ }^{41}$.

A partir desses critérios, é possível asseverar que o Tribunal Europeu não leva em conta somente a quantidade de tempo na tramitação do processo desde o seu nascedouro. Segundo a Corte, faz-se necessária, também, uma análise casuística para que se possa reconhecer se houve ou não a indevida dilação temporal. Isso porque as demais garantias processuais não podem ser forjadas somente em razão da celeridade, já que os princípios do contraditório e da ampla defesa também se configuram como direitos fundamentais e importantes à efetivação da Justiça. Nesse sentido, convém salientar que por razoável duração do processo não se designa, como salienta Marinoni $^{42}$, celeridade processual apenas: "não há como pensar em duração razoável quando as partes não podem participar do processo de modo adequado". Logo, o direito à duração razoável do processo também compreende - para além da tutela jurisdicional tempestiva - o direito ao prazo adequado para prática de atos processuais e o direito a não ter a sua esfera jurídica restringida por um lapso temporal desnecessário.

Em razão disso, segundo a análise de $S_{c h e n k}{ }^{43}$, a

${ }_{41}$ Importante observar, nesse ponto, que a Corte Europeia de Direitos Humanos leva em consideração, no tratamento dispensado ao tema da morosidade, aquilo a que SANTOS, Boaventura de Sousa. Para uma revolução democrática da justiça. São Paulo: Cortez, 2007. p. 42-43 denomina de "morosidade ativa", estabelecendo uma distinção entre esta e a chamada morosidade sistêmica: esta "é aquela que decorre da burocracia, do positivismo e do legalismo", ao passo que aquela "consiste na interposição, por parte de operadores concretos do sistema judicial (magistrados, funcionários ou partes), de obstáculos para impedir que a sequência normal dos procedimentos desfechem o caso."

42 MARINONI, Luiz Guilherme. Direito fundamental à duração razoável do processo. Estação Científica, Juiz de Fora, v. 1 , n. 4 , p. 90 , out./nov. 2009.

43 SCHENK, Leandro Faria. Notas sobre o modus operandi das cortes europeia e interamericana para a aferição das violações do direito à razoável duração dos processos. $R e$ vista Síntese de Direito Civil e Processual Civil, Porto Alegre, 
Corte Europeia, quando decide acerca de eventuais violações ao art. $6^{\circ}$, I, da Convenção, observa, primeiramente, o período de tempo a ser levado em consideração diante do caso concreto. Nos casos em que há indícios de abuso, a Corte avalia a complexidade do caso, bem como o comportamento processual da parte recorrente e das autoridades envolvidas e, por fim, a importância do litígio. Reconhecida a violação, invariavelmente a Corte decide, em prol da parte afetada, pelo estabelecimento de uma reparação pecuniária em decorrência dos danos patrimoniais e extrapatrimoniais gerados pela demora.

É possível afirmar, portanto, que existe, na realidade europeia uma crescente preocupação com o aperfeiçoamento da qualidade do serviço prestado pelo sistema de administração da justiça. Isso tem incentivado a adoção, por muitos países da Europa, de métodos alternativos de resolução de controvérsias, os quais são chamados $\mathrm{ADR}$ (alternative dispute resolution). Esses mecanismos originaram-se nos Estados Unidos, onde a expressão ADR é "reservada para designar todos os procedimentos de resolução de disputas sem a intervenção de uma autoridade judicial" ${ }^{44}$. Diante de problemas apresentados pelos sistemas judiciários, os países europeus passaram paulatinamente a aceitar as ADR para resolver conflitos cotidianos que emergem em suas sociedades. Na realidade francesa, referidos mecanismos são utilizados para a solução, por exemplo, de conflitos de vizinhança, e têm por objetivo sensibilizar os habitantes de um determinado local/região para a gestão dos seus conflitos e consequente redução da tensão social, criando um espaço de solidariedade a partir da participação de todos na resolução dos conflitos. Como ressaltam Pedroso e Cruz ${ }^{45}$, “o modelo que repousa sobre a oposição de interesses revela-se desajustado a questões caracterizadas por relações continuadas como é o caso das relações familiares, das relações de vizinhança, [...] e, também, de trabalho." Diante dessa constatação, a partir das experiências de justiça consensual, "as partes são incentivadas a chegar a um acordo sobre um comportamento futuro, em detrimento

v. 12, n. 84, p. 92-105, jul./ago. 2013.

44 SPENGLER, Fabiana. Da jurisdição à mediação: por uma outra cultura no tratamento de conflitos. Ijuí: Unijuí, 2010. p. 295.

45 PEDROSO, João; CRUZ, Cristina. A arbitragem institucional: um novo modelo de administração de justiça: o caso dos conflitos de consumo. Coimbra, 2000. Disponível em: $<$ http://opj.ces.uc.pt/portugues/relatorios/relatorio_0,9. html>. Acesso em: 08 set. 2015. de se efectuar um julgamento confinado aos precedentes legais e leis acerca de comportamentos passados".

Esse esforço pela implementação das ADR culminou na edição da Diretiva 2008/52/EU ${ }^{46}$, a qual incentiva o uso da mediação no âmbito da Europa. O item 5 dos "Considerando" da Diretiva reza que, a partir do "objetivo de assegurar um melhor acesso à justiça, como parte da política da União Europeia para estabelecer um espaço de liberdade, de segurança e de justiça” pressupõe a inclusão do "acesso a modos de resolução de litígios tanto judiciais como extrajudiciais", razão pela qual a Diretiva "deverá contribuir para o correto funcionamento do mercado interno, em especial no que diz respeito à disponibilidade de serviços de mediação”. Ainda em seus Considerandos, o texto da Diretiva supõe a eficácia dos acordos obtidos amigavelmente por meio da mediação (6), bem como a necessidade de um enquadramento normativo da matéria (7).

Em que pese o fato de a Diretiva se destinar à mediação de litígios transfronteiriços, não há nenhum fator que impeça os Estados-membros de aplicar o instituto internamente (Considerando 8). Por fim, a Diretiva também salienta que a mediação não deve ser considerada como alternativa que ocupa posição inferior à ocupada pelo processo judicial (Considerando 19), o que contribui para a elevação da dignidade desse método alternativo de resolução de conflitos, fomentando, reflexamente, a sua promoção nos países europeus ${ }^{47}$.

A realidade italiana merece uma análise mais detida sobre a adoção da mediação em seu direito interno, principalmente no que diz respeito à previsão de obriga-

46 "The enactment of the Directive 2008/52/EC shows a clear commitment of the European Union for mediation. Its final transposition in the several EU Member States shows the quest for a new notion of "access to justice" in Europe. Complex situations require complex solutions and in the field of justice this implies a deep change in the understanding of the aforementioned principle. Access to justice may not any longer imply a reference to access to State Courts. On the contrary, a multiple option is now open to citizens for the resolution of their disputes: they may refer them to State Courts or they are free to resource to ADR devices" . ESPLUGUES, Carlos. Access to justice or access to states courts' justice in Europe? The directive 2008/52/EC on civil and commercial mediation. Revista de Processo, São Paulo, v. 38, n. 221, p. 303-333, jul. 2013.

47 "Alla giustizia rappresentata dalla spada che taglia, che recide, si sostituisce la conciliazione rappresentata dall'agnello". PISANI, Andrea Proto. Appunti su mediazione e conciliazione. Revista de Processo, São Paulo, v. 187, p. 231238, set. 2010. p. 233. 
toriedade na utilização das ADR enquanto condição de admissibilidade da ação. Essa medida assume especial relevância diante do fato de que a morosidade dos processos judiciais italianos foi responsável por causar uma sobrecarga de demandas na Corte Europeia: foram inúmeras as reclamações na Corte acerca do desrespeito do país com o preconizado pelo art. 6, I, da Convenção Europeia ${ }^{48}$.

Sob pressão dos demais países União Europeia, a Itália diligenciou na edição de uma lei que trata do pagamento de indenização para as pessoas que sofrem prejuízo em razão do excesso de tempo na tramitação de processos judiciais (Lei $\mathrm{n}^{\circ}$ 89/2001). Posteriormente, a Lei $\mathrm{n}^{\circ}$ 69, de 18 de junho de 2009 autorizou, em seu artigo 60, a edição de Decreto pelo governo, com o objetivo de regulamentar a mediação no âmbito do direito civil e comercial. O Decreto 28/2010, então, foi responsável pela introdução, na Itália, da disciplina da mediação civil e comercial, atendendo ao disposto na Diretiva 52/2008.

O Decreto em questão prevê três modalidades de mediação: a facoltatvia, a concordata e a obbligatoria. A mediação obbligatoria está prevista no artigo 5 do referido diploma, e é objeto de intenso debate no país, por conta das consequências processuais que decorrem da compulsoriedade do instituto ${ }^{49}$. No final do ano de 2012, a Corte Constitucional italiana proferiu o acórdão no 272/2012, no qual declara inconstitucionais algumas disposições do Decreto $n^{\circ}$ 28/2010, incluindo o artigo 5, n. 1, que trata a mediação como condição de procedibilidade de ação. Em face disso, o poder Executivo, em agosto de 2013, eliminou a incompatibilidade do instituto, com a ratificação da obrigatoriedade da mediação, medida responsável pelo abrandamento das críticas, o que se deve também ao fato de que o poder Executivo previu, ao ratificar a obrigatoriedade da mediação, que ela deve ser necessariamente assistida por um advogado.

48 HOFFMAN, Paulo. O direito à razoável duração do processo e a experiência italiana. Disponível em: <http://jus.com. br/artigos/7179>. Acesso em: 11 dez. 2015.

49 "Diante disso, algumas associações profissionais ingressaram com ação em face do Ministério da Justiça e do Ministério do Desenvolvimento Econômico perante o TAR Lazio que decidiu em 2011, não serem infundadas as dúvidas suscitadas acerca de alguns dispositivos do Decreto Legislativo 28/2010, tais como a excessiva delegação constante no art. $5 .^{\circ}$, e que a mediação enquanto fase de pré-julgamento, traduzindo condição de admissibilidade da ação, impede efetivamente o acesso à Justiça". PINHO, Humberto Dalla Benardina de. A mediação e o código de processo civil projetado. Revista de Processo, São Paulo, v. 37, n. 207, p. 213-238, maio 2012. p. 220.
No Brasil, o novo Código de Processo Civil trata da mediação e da conciliação como instrumentos facultativos. No entanto, dispõe o novo Código que essas práticas devem ser estimuladas por todos os operadores do direito (art. 145), estabelecendo como obrigação para o juiz a tentativa - prioritária e a qualquer tempo - de compor amigavelmente o litígio, de preferência por meio do auxílio de conciliadores e de mediadores (art. 118, IV).

Como se procurou demonstrar, os institutos da mediação e da conciliação como formas de contribuição para um processo mais célere também encontram guarida no ordenamento jurídico brasileiro. O país, assim como os demais países que formam o Continente Americano, à semelhança do que ocorre com os países europeus, também se vê estimulado a adotar métodos consensuais de resolução de conflitos, tema que será abordado no tópico que segue.

\section{0 direito à razoável duração do processo na realidade americana e perante a Corte Inte- ramericana De Direitos Humanos}

Assim como ocorre no Sistema Regional Europeu de Direitos Humanos, o continente americano também possui um Sistema Regional de Proteção, denominado de Sistema Interamericano. O principal texto jurídico desse sistema é a chamada Convenção Americana de Direitos Humanos (1969), a qual estabeleceu a criação da Comissão Interamericana e da Corte Interamericana de Direitos Humanos.

A atuação da Corte Interamericana de Direitos Humanos leva em consideração as pecualiaridades da América Latina, considerando que, na região, as violações de Direitos Humanos são, em sua maior parte, consequência de um alto grau de violência estrutural e exclusão que se apresentam nas sociedades de seus países-membros. Ainda, deve-se considerar que muitas democracias da região ainda estão em fase de consolidação, o que impõe inúmeros desafios à proteção de direitos ${ }^{50}$.

A Convenção Americana de Direitos Humanos - também denominada de "Pacto de São José da Costa Rica" - além de instituir a Comissão e a Corte Interame-

50 PIOVESAN, Flavia. Sistema Interamericano de Direitos Humanos: impacto transformador, diálogos jurisdicionais e os desafios da reforma. Revista de Estudos Constitucionais, Hermenêutica e Teoria do Direito, São Leopoldo, v. 6, n. 2, p. 142-154, jul./set. 2014. 
ricana de Direitos Humanos, buscou assegurar um rol de direitos civis e políticos que devem ser cumpridos pelos Estados-membros. No art. $8^{\circ}$ da Convenção, que dispõe sobre as garantias judiciais, há previsão expressa do direito à razoável duração do processo, in verbis:

1. Toda pessoa tem direito a ser ouvida, com as devidas garantias e dentro de um prazo razoável, por um juiz ou tribunal competente, independente e imparcial, estabelecido anteriormente por lei, na apuração de qualquer acusação pena formulada contra ela, ou para que se determinem seus direitos ou obrigações de natureza civil, trabalhista, fiscal ou de qualquer outra natureza.

Segundo Leandro Schenk ${ }^{51}$, a instituição da duração razoável do processo almeja alcançar duas finalidades. A primeira, em nível abstrato, refere-se ao direito humano a um julgamento devido; já a segunda, em nível concreto, refere-se ao acesso direto ao sistema internacional, prescindindo, para tanto, da exigência do prévio esgotamento recursal da jurisdição interna, sempre que ocorrer demora injustificada na apreciação desses recursos (art. 46, item 2, c, da Convenção).

Uma breve pesquisa no sítio virtual da Corte Interamericana ${ }^{52}$ permite verificar que o Brasil possui condenação perante aquele órgão em decorrência de violação de garantias judiciais. No emblemático caso Ximenes Lopes (2006), a Corte Interamericana salienta, no item III da ficha técnica do caso, a ocorrência de negligência das autoridades encarregadas pela investigação da morte de Damião Ximenes Lopes. Além disso, reconhece que procrastinação do processo judicial pode ser atribuída exclusivamente às condutas judiciais. Entendeu a Corte não ser razoável que, depois de seis anos do início da ação penal, ainda não se tenha obtido uma sentença de primeiro grau. Em razão disso, o Brasil foi condenado a pagar o valor equivalente a 148 mil dólares aos familiares de Damião. Também foi determinada a ultimação da investigação processual, entre outras medidas ${ }^{53}$.

51 SCHENK, Leandro Faria. Notas sobre o modus operandi das cortes europeia e interamericana para a aferição das violações do direito à razoável duração dos processos. Revista Síntese de Direito Civil e Processual Civil, Porto Alegre, v. 12, n. 84 , p. $92-105$, jul./ago. 2013.

52 CORTE INTERAMERICANA DE DERECHOS HUMANOS. [Homepage]. Disponível em: <http://www.corteidh. or.cr/cf/Jurisprudencia2/index.cfm?lang=es $>$. Acesso em: 11 dez. 2015.

53 SCHENK, Leandro Faria. Notas sobre o modus operandi das cortes europeia e interamericana para a aferição das violações do direito à razoável duração dos processos. $R e$ vista Síntese de Direito Civil e Processual Civil, Porto Alegre,
O mesmo se pode observar no caso Maria da Penha (1998). Mesmo não tendo chegado ao conhecimento da Corte, a Comissão Interamericana de Direitos Humanos, ao apreciar a questão, considerou que o Brasil não observou as garantias judiciais expressas no art. 8 do Pacto de São José da Costa Rica. No relatório elaborado pela Comissão, lê-se que, na data da submissão da petição ao órgão, a justiça brasileira havia postergado o processo penal por mais de quinze anos sem que se chegasse à condenação definitiva do ex-marido agressor. Entendeu-se, então, que era desnecessário o prévio esgotamento das vias recursais internas para acessar o sistema internacional, diante do grande e injustificado atraso na solução do caso pelo Judiciário brasileiro.

No caso da Guerrilha do Araguaia (também conhecido como caso Gomes Lund), de 2008, também é possível verificar uma preocupação do Sistema Interamericano de Direitos Humanos em relação ao direito fundamental à razoável duração do processo. A Corte Interamericana entendeu que o Brasil deveria assegurar aos familiares das vítimas de desaparecimento forçado no conflito a investigação, dentro de um prazo razoável, acerca da veracidade dos fatos, bem como da aplicação de eventuais sanções. Na decisão em comento, a Corte declarou que a discussão sobre os crimes de desaparecimento forçado, de tortura e execução sumária que foram praticados pelo Estado brasileiro para reprimir a Guerrilha do Araguaia, são exemplos inacabados de crime de lesa-humanidade e, nessa condição, requerem um tratamento diferenciado, de modo que o seu julgamento não pode ser inviabilizado pelo decurso do tempo, com a prescrição, ou por dispositivos normativos de anistia.

A partir do até aqui exposto, é possível afirmar que o Brasil, enquanto país signatário da Convenção Americana de Direitos Humanos e dotado de um Texto Constitucional que prevê de modo expresso que os direitos e garantias fundamentais não se esgotam no rol estabelecido em seu artigo $5^{\circ}$, mas também que decorrem "do regime e dos princípios por ela adotados, ou dos tratados internacionais em que a República Federativa seja parte" (art. 5º, $\left.\$ 2^{\circ}\right)$, já estava submetido à razoável duração do processo muito antes da promulgação da Emenda Constitucional $45 / 2004^{54}$. Isso porque o Decreto $n^{\circ} 678$, que promulgou

v. 12, n. 84, p. 92-105, jul./ago. 2013.

54 Nesse ponto, é importante salientar que a doutrina constitucional brasileira dissente de uma visão estritamente "topográfica" dos direitos fundamentais a partir do Texto 
o Pacto de São José da Costa Rica, encontra-se em vigor desde 1992.

Na sequência, ainda no âmbito latino-americano, em se tratando especificamente da mediação e da conciliação, convém trazer ao debate algumas considerações acerca desses institutos na realidade argentina. $\mathrm{O}$ ordenamento daquele país estabelece a mediação preliminar compulsória há mais de dezoito anos. Nos termos da Lei $n^{\circ} 24.573 / 1995$, houve, inicialmente, a previsão da obrigatoriedade da mediação prévia pelo prazo de cinco anos, durante o qual "la ciudadanía y los abogados modificarían sus patrones culturales (adversos a la autocomposición), y, por el otro, el Estado desarrollaría su proyecto de renovación total de la manera de hacer justicia"55. Ocorre que, uma vez transcorrido o prazo estipulado pela Lei em comento, nem uma coisa nem outra havia ocorrido, o que levou a mais duas prorrogações dessa obrigação, processo que culminou, no ano de 2010, com a edição da Lei no 26.589, que passou a regular a mediação obrigatória de forma definitiva. Ainda, a recente legislação estabeleceu a tarefa de mediador como exclusiva à figura do advogado que possua, no mínimo, três anos de experiência ${ }^{56} 57$.

Constitucional. Reconhece-se que esses direitos podem ser encontrados até mesmo fora do catálogo constitucional, uma vez que se reconhece que existe um catálogo de direitos materialmente fundamentais - segundo a classificação de CANOTILHO, J. J. Gomes. Direito constitucional e teoria da constituição. 7. ed. Coimbra: Almedina, 2000 - que é aberto. Ou seja: existem direitos que, pela sua essência, são (materialmente, portanto) fundamentais, sendo irrelevante a sua positivação sob a forma constitucional. Pode-se falar, a propósito, no surgimento de um direito constitucional internacional, que parte do pressuposto de que existe uma indissolúvel e essencial unidade entre os direitos humanos reconhecidos em âmbito internacional e os direitos fundamentais reconhecidos em âmbito interno.

55 GIANNINI, Leandro J. Mediación, paternalismo e incentivos (la experiencia de la mediación obligatoria en Argentina). Revista de Processo, São Paulo, v. 39, n. 228, p. 379-405, fev. 2014.

56 GIANNINI, Leandro J. Mediación, paternalismo e incentivos (la experiencia de la mediación obligatoria en Argentina). Revista de Processo, São Paulo, v. 39, n. 228, p. 379-405, fev. 2014.

57 Mesmo em face dos números alentadores da pesquisa realizada na Argentina, as críticas quanto à obrigatoriedade do instituto da mediação no país ainda permanecem vivas, tal como ocorre na Itália, "porque no es la imposición de ese deber el verdadero camino para romper patrones culturales o para llegar a soluciones negociadas socialmente virtuosas, sino la supervisión y corrección de los restantes incentivos que multiplican la litigiosidad o fuerzan a resignarse ante la injusticia." GIANNINI, Leandro J. Mediación, paternalismo e incentivos (la experiencia de la mediación obligatoria en Argentina). Revista de Processo, São Paulo, v.
Diversamente do que ocorre no Brasil, a Argentina apresenta relatórios contendo dados estatísticos que servem para demonstrar os resultados positivos alcançados pela mediação ao longo do prazo em que o instituto encontra-se previsto no ordenamento nacional: das mediações levadas a cabo na capital Buenos Aires, 65\% não alcança a via judicial; além disso, o número de ajuizamento de novas ações na capital reduziu no percentual de $30,59 \%{ }^{58}$. Em boa medida, a falta de dados estatísticos no Brasil se deve à recente implantação de uma política de meios alternativos de resolução de conflitos (por meio da Resolução no 125 do Conselho Nacional de Justiça, datada de 2010). Ainda, pode-se atribuir a escassez de dados à falta de regulação legal da matéria, considerando que a Lei da Mediação (Lei 13.140/2015) foi sancionada recentemente, em 26 de junho de 2015.

Por fim, não se pode deixar de mencionar, ainda que sucintamente, a utilização de meios alternativos de solução de litígios nos Estados Unidos, país no qual a ADR foi concebida. No sistema de administração de justiça americano é possível evidenciar um rito processual mais célere, no qual se priorizam os debates orais, os acordos, a produção de provas pelas próprias partes, etc ${ }^{59}$. Na resolução de conflitos que envolvem Direito de Família, por exemplo, Pedroso e Cruz ${ }^{60}$, salientam, a partir da utilização das ADR nos Estados Unidos, que “a mediação permite passar de um 'direito imposto' para um 'direito negociado', dado, por exemplo, ser possível às partes fixarem por acordo o montante da pensão alimentar paga por um dos pais".

A incorporação das ADR na cultura judiciária

39, n. 228, p. 379-405, fev. 2014. p. 385.

58 GIANNINI, Leandro J. Mediación, paternalismo e incentivos (la experiencia de la mediación obligatoria en Argentina). Revista de Processo, São Paulo, v. 39, n. 228, p. 379-405, fev. 2014.

59 Como salienta CARDOSO, César. O pré-julgamento (petrail) e a conciliação como instrumentos de desoneração do sistema judicial norte-americano: um paralelo com o sistema brasileiro. Publicações da Escola da AGU, Brasília, v. 1, n. 12, p. 77-89, set./out. 2011. p. 87, "o sistema judicial e o processo nos Estados Unidos são estruturados de modo a atribuir a maior parte da responsabilidade pela solução dos litígios aos litigantes e seus advogados. Ao magistrado cumpre intervir ou para incentivar um acordo ou para decidir na hipótese de um acordo se mostrar inviável, esgotadas todas as tentativas".

60 PEDROSO, João; CRUZ, Cristina. A arbitragem institucional: um novo modelo de administração de justiça: o caso dos conflitos de consumo. Coimbra, 2000. Disponível em: $<$ http://opj.ces.uc.pt/portugues/relatorios/relatorio_0,9. html>. Acesso em: 08 set. 2015. 
norte-americana deve-se ao fato de que o poder judiciário do país também se depara com um grande número de demandas ${ }^{61}$. É dos Estados Unidos que se origina o chamado "Sistema de Múltiplas Portas" (Multi-door Courthouse System). Criado pelo professor de Harvard Frank Sander, em 1979, esse sistema propõe que o cidadão em busca da resolução de um litígio se submeta a uma espécie de "triagem" prévia, na qual ocorre uma avaliação do melhor método para a solução do problema. Esse sistema serve para desmitificar a cultura de exclusividade do sistema judicial para a solução de controvérsias, funcionando como um importante mecanismo de implantação de uma cultura de resolução de conflitos por meios alternativos.

\section{Considerações Finais}

Os conflitos são inerentes às relações humanas. Logo, assim como essas relações, as tentativas para a resolução (ou mitigação) de litígios são variáveis, dinâmicas, nem sempre marcadas pela ideia de eficácia. O sistema de administração da justiça institucionalizado delega ao Estado o monopólio da resolução de controvérsias. Isso ocorre por meio de regras que são positivadas no ordenamento jurídico de cada país e que estabelecem, como regra, o processo judicial como rito incontornável para se obter um resultado final.

A partir do momento em que se constata a ineficiência desse sistema para resolver a incessante quantidade de conflitos que afloram das relações humanas, passa-se a pensar em um conjunto de alternativas à jurisdição. Nesse sentido, como se procurou demonstrar com o presente artigo, a adoção de métodos alternativos de resolução de conflitos é uma realidade ainda recente no Brasil, quando comparada à situação de outros países que também adotam o sistema da civil law.

Evidenciou-se que na Europa já se criou uma cultura de utilização de meios alternativos de resolução de conflitos que está incorporada aos ordenamentos jurídicos de vários países. Isso viabiliza, no caso brasileiro, por meio de uma análise de Direito Comparado, que sejam avaliadas as experiências adotadas pelos ordenamentos estrangeiros, de modo que se possa aplicar, no âmbito

61 SILVA, Vládia Pompeu. Multi-door courthouse system: o exemplo norte-americano na busca da efetivação do acesso à justiça e experiência brasileira na utilização do novo sistema. Publicações da Escola da AGU, Brasília, v. 1, n. 12, p. 363-383, set./out. 2011. interno, a(s) melhor (es) técnica(s) quando da regulação desses sistemas consensuais, o que parece se evidenciar pela redação do novo Código de Processo Civil, bem como da promulgação da Lei da Mediação, diplomas que, mesmo não prevendo a obrigatoriedade da adoção de tais métodos, estimulam a sua prática.

A obrigatoriedade da utilização das ADR, como se procurou mostrar, ainda é alvo de severas críticas nos países que adotaram a medida - a exemplo das experiências italianas e argentinas, abordadas no texto. De fato, o fundamento de uma solução consensual a um determinado litígio parece não harmonizar com a sua utilização obrigatória pelas partes. Afinal, a autonomia dos indivíduos envolvidos em um conflito exige uma assimilação dos benefícios da mediação, o que não se obtém por meio da mera obediência a uma condição de procedibilidade da ação.

A preocupação com um sistema judicial eficiente e que responda tempestivamente às demandas que lhe são propostas encontra-se expressa tanto na Convenção Europeia quanto na Convenção Americana de Direitos Humanos. No caso do Brasil, mesmo que o país seja signatário desse último documento de direito internacional, os números expressos nos relatórios elaborados pelo Conselho Nacional de Justiça apontam não só a demora na satisfação de um resultado por meio do processo judicial, bem como que o país retardou em muito a adoção de medidas para tornar seu Judiciário mais eficiente e para incentivar a utilização de métodos outros que não o processo judicial para a solução de controvérsias. Disso resultaram, inclusive, condenações ao país perante a Comissão e a Corte Interamericana de Direitos Humanos, como evidenciado ao longo do texto a partir dos Casos Ximenes Lopes, Maria da Penha e Gomes Lund (Guerrilha do Araguaia).

Não obstante a constatação de que o Poder Judiciário brasileiro não mais responde com eficiência às funções que lhe são designadas pelo Texto Constitucional brasileiro, entende-se que a incorporação das práticas alternativas de solução de conflitos no país não será atingida somente por meio de sua previsão legal. Isso porque a sociedade brasileira ainda possui traços paternalistas, o que a leva a creditar ao Estado a resolução de seus problemas, vislumbrando no juiz a única figura com "autoridade" para a resolução de controvérsias. Por outro lado, o país assiste a uma valorização das práticas consensuais de resolução de conflitos, o que permite vislumbrar mudan- 
ças paradigmáticas que poderão resultar em uma maior eficácia na solução de controvérsias.

\section{Referências}

ASSOCIAÇÃO DOS MAGISTRADOS DO BRASIL. O uso da Justiça e o litígio no Brasil. Disponível em: <https:// www.placardajustica.com.br/assets/files/placardajustica_o_uso_da_justica_e_o_litigio_no_brasil.pdf >. Acesso em: 01 set. 2015.

BESSO, Chiara. La medizione italina: definizione e tipologie. Revista Eletrônica de Direito Processual, Rio de Janeiro, v. 6, p. 248-269, jul./dez. 2010.

BOBBIO, Norberto. A era dos direitos. Rio de Janeiro: Campus, 1992.

CANOTILHO, J. J. Gomes. Direito constitucional e teoria da constituição. 7. ed. Coimbra: Almedina, 2000.

CAPPELLETTI, Mauro. Acesso à justiça. Porto Alegre: S. A. Fabris, 1988.

CAPPELLETTI, Mauro. Juízes legisladores? Tradução Carlos Alberto Alvaro de Oliveira. Porto Alegre: S. A. Fabris, 1993.

CARDOSO, César. O pré-julgamento (petrail) e a conciliação como instrumentos de desoneração do sistema judicial norte-americano: um paralelo com o sistema brasileiro. Publicações da Escola da AGU, Brasília, v. 1, n. 12, p. 7789, set./out. 2011.

CORTE INTERAMERICANA DE DIREITO HUMANOS. Caso Gomes Lund y otros (Guerrilha do Araguaia) vs. Brasil. Disponível em: <http://www.corteidh.or.cr/ docs/casos/articulos/seriec_219_esp.pdf $>$. Acesso em: 25 out. 2015.

CRUZ, Rossana Martingo. A importância da União Europeia no fomento da mediação em Portugal. Disponível em: <europe-direct-aveiro.aeva.eu/debatereuropa/images/n9/rcruz.pdf>. Acesso em: 11 dez. 2015.

DINAMARCO, Cândido Rangel. A instrumentalidade do processo. 7. ed. São Paulo: Malheiros, 1999.

ESPLUGUES, Carlos. Access to justice or access to states courts' justice in Europe? The directive 2008/52/EC on civil and commercial mediation. Revista de Processo, São Paulo, v. 38, n. 221, p. 303-333, jul. 2013.

FARIA, José Eduardo. O sistema brasileiro de Justiça: experiência recente e futuros desafios. Estudos avançados, São Paulo, v. 18, n. 51, p. 103-125, jan./abr. 2004.

GARAPON, Antoine. Bem julgar. Lisboa: Instituto Piaget, 1997.
GIANNINI, Leandro J. Mediación, paternalismo e incentivos: la experiencia de la mediación obligatoria en Argentina. Revista de Processo, São Paulo, v. 39, n. 228, p. 379-405, fev. 2014.

HOFFMAN, Paulo. O direito à razoável duração do processo e a experiência italiana. Disponível em: $<\mathrm{http}$ ://jus. com.br/artigos/7179>. Acesso em: 11 dez. 2015.

MARINONI, Luiz Guilherme. Direito fundamental à duração razoável do processo. Estação Científica, Juiz de Fora, v. 1, n. 4, out./nov. 2009.

MARINONI, Luiz Guilherme; ARENHART, Sérgio Cruz; MITIDIERO, Daniel. Novo curso de processo civil: tutela dos direitos mediante procedimento comum. São Paulo: Revista dos Tribunais, 2015.

MAZZUOLI, Valério de Oliveira. O Sistema Regional Europeu de Proteção dos Direitos Humanos. Revista de Direito Constitucional e Internacional, São Paulo, v. 71, p. 345-374, abr./jun. 2010.

MORAIS, Jose Luis Bolzan de. Mediação e arbitragem: alternativas à jurisdição. Porto Alegre: Livraria do Advogado, 1999.

NALINI, José Renato. Morosidade do Judiciário: causas normativas, conjunturais e culturais. Propostas de enfrentamento. Revista Forense, Rio de Janeiro, v. 104, n. 399, p. 129-144, set./out. 2008.

PEDROSO, João; CRUZ, Cristina. A arbitragem institucional: um novo modelo de administração de justiça: o caso dos conflitos de consumo. Coimbra, 2000. Disponível em: <http://opj.ces.uc.pt/portugues/relatorios/relatorio_0,9.html>. Acesso em: 08 set. 2015.

PINHO, Humberto Dalla Benardina de. A mediação e o código de processo civil projetado. Revista de Processo, São Paulo, v. 37, n. 207, p. 213-238, maio 2012.

PINHO, Humberto Dalla Bernardina de. O novo CPC e a mediação: reflexões e ponderações. Revista de Informação Legislativa, Brasília, v. 48, n. 190, t. 1, p. 219-235, abr./jun. 2011.

PIOVESAN, Flavia. Sistema Interamericano de Direitos Humanos: impacto transformador, diálogos jurisdicionais e os desafios da reforma. Revista de Estudos Constitucionais, Hermenêutica e Teoria do Direito, São Leopoldo, v. 6, n. 2, p. 142-154, jul./set. 2014.

PISANI, Andrea Proto. Appunti su mediazione e conciliazione. Revista de Processo, São Paulo, v. 187, p. 231-238, set. 2010.

SADEK, Maria Tereza. Judiciário: mudanças e reformas. Estudos Avançados, São Paulo, v. 18, n. 51, p. 79-101, jan./ abr. 2004. 
SALDANHA, Jânia Maria Lopes. Da teoria geral do processo à teoria da tradução: um aporte da sociologia das ausências e das emergências. In: DIDIER JUNIOR, Fredie; JORDÃO, Eduardo Ferreira (Org.). Teoria do processo: panorama doutrinário mundial. Salvador: JusPodivm, 2007. p. 389-428.

SALES, Lilia Maria de Morais Sales; RABELO, Cilana de Morais Soares. Meios consensuais de solução de conflitos: instrumentos de democracia. Revista de Informação Legislativa, Brasília, v. 46, n. 182, p. 75-88, abr./jun. 2009.

SANTOS, Boaventura de Sousa. Para uma revolução democrática da justiça. São Paulo: Cortez, 2007.

SCHENK, Leandro Faria. Notas sobre o modus operandi das cortes europeia e interamericana para a aferição das violações do direito à razoável duração dos processos. Revista Síntese de Direito Civil e Processual Civil, Porto Alegre, v. 12, n. 84, p. 92-105, jul./ago. 2013.

SILVA, Enio Moraes da. A garantia constitucional da razoável duração do processo e a defesa do Estado. Revista de Informação Legislativa, Brasília, v. 43, n. 172, p. 23-36, out./dez. 2006.

SILVA, Vládia Pompeu. Multi-door courthouse system: o exemplo norte-americano na busca da efetivação do acesso à justiça e experiência brasileira na utilização do novo sistema. Publicações da Escola da AGU, Brasília, v. 1, n. 12, p. 363-383, set./out. 2011.
SPENGLER, Fabiana. Da jurisdição à mediação: por uma outra cultura no tratamento de conflitos. Ijuí: Unijuí, 2010.

STRECK, Lenio Luiz. Hermenêutica jurídica e $(m)$ crise: uma exploração hermenêutica da construção do Direito. 8. ed. rev. e atual. Porto Alegre: Livraria do Advogado, 2008.

TUCCI, José Rogério Cruz e. Garantias constitucionais da duração razoável e da economia processual no projeto do código de processo civil. Revista de Processo, São Paulo, v. 192, p. 193-208, fev. 2010.

WATANABE, Kazuo. Política Pública do Poder Judiciário nacional para tratamento adequado dos conflitos de interesses. Revista de Processo, São Paulo, v. 195, p. 381-389, maio 2011.

ZAMPIERI, Natália. A efetividade da razoável duração do processo e a gestão pública. Revista de Processo, São Paulo, v. 39, n. 234, p. 13-30, ago. 2014. 